\title{
New distribution Record of Phrynocephalus mystaceus Pallas 1776 (Sauria: Agamidae) from Iran
}

\author{
Farahnaz Molavi ${ }^{1}$, Tooba Mohammadian-kalat ${ }^{2 *}$, Bahram Hasanzade Kiabi ${ }^{3}$, Haji Gholi Kami ${ }^{4}$ and \\ Morteza Yazdanpanahi ${ }^{3}$
}

\footnotetext{
1 Islamic Azad University, Mashhad Branch, Faculty of science, Department of Biology, Mashhad, Iran.

2 Ferdowsi University of Mashhad, Faculty of Sciences, Department of Biology, Mashhad, Iran.

3 Shahid Beheshti University, Faculty of Science, Department of Biology, Tehran, Iran.

4 University of Agricultural Sciences and Natural Resources, Faculty of Science, Department of Biology, Gorgan, Iran.

* Corresponding author. E-mail: tmohammadian@gmail.com
}

\begin{abstract}
The Toad-headed agama, Phrynocephalus mystaceus Pallas 1776, was described in 1999 from eastern Khorasan by Anderson. Seven specimen of The Toad-headed agama were collected in Khar Turan National Park during fieldwork from June 2008 to June 2009. The new locality of the species is situated about $900 \mathrm{~km}$ west of the type locality. This record indicates a wider distribution of Phrynocephalus mystaceus on the Iranian plateau than previously thought. Information on morphological characters and habitat is presented.
\end{abstract}

Toad-headed agamas, Phrynocephalus Kaup, 1825, are distributed from southern Europe and southwest Asia (including the Arabian Peninsula and northern India) through central and Middle Asia to East Asia (northern China and Mongolia). This further demonstrates that the taxonomic diversity of Phrynocephalus in Iran is ambiguous. Currently there are approximately 40 species of Toad-headed Agamas of the genus Phrynocephalus, seven of which have been recorded from Iran (Anderson, 1999). However, Golubev \& Sattorov (1992) recorded ten species of Phrynocephalus from Southwest and middle Asia. The best diagnostic character of Phrynocephalus mystaceus is a large fringed cutaneous fold at angle of mouth. Ananjeva (1986) refers this species to the monotypic genus Megalochilus, but Golubev argue that the differences are too slight to warrant a separate genus (Golubev and Sattorov, 1992). In this study, we report new

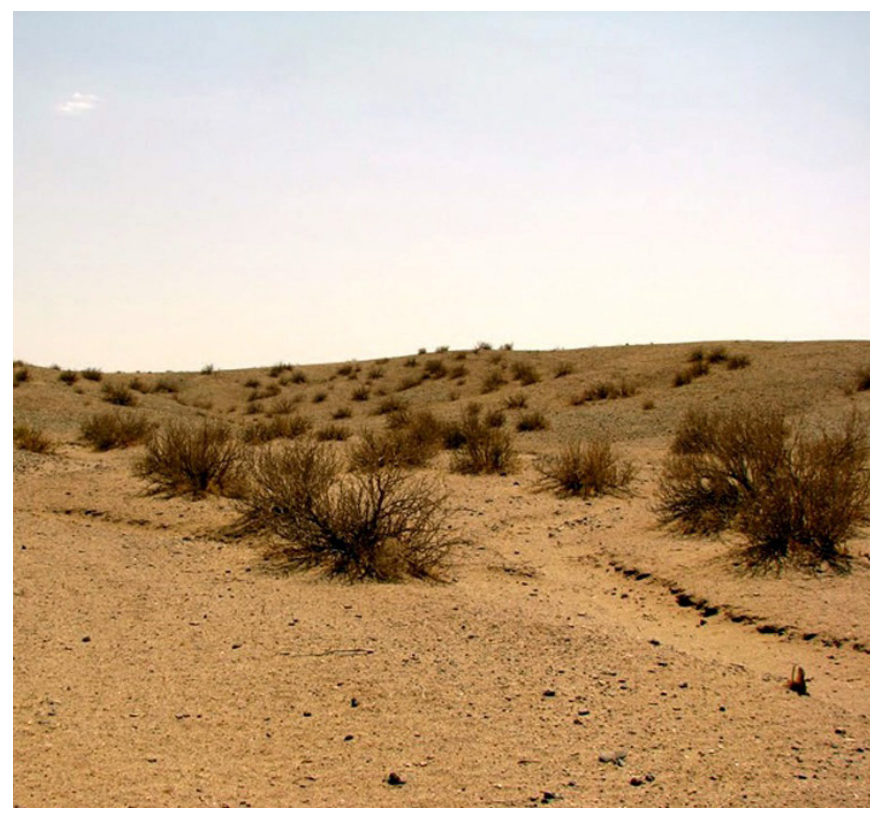

FIGURE 1. Habitat of Phrynocephalu smystaceus. data on morphological characters and sexual dimorphism with a range extension for $P$. mystaceus in Iran.

Seven specimens of $P$. mystaceus were collected in June 2008-9 from Khar Turan National Park in Semnam province (Figure 1). This locality is located in a sandy area of eastern part of Ahmad Abad village $\left(35^{\circ} 48^{\prime} \mathrm{N}, 56^{\circ} 42^{\prime}\right.$ E) $1000 \mathrm{~m}$ above sea level (Figure 2). Haloxylon sp. and Tamarix sp. are dominant plant species of this locality.

Specimens were captured alive for study of their behavior in the laboratory, and later were preserved in $10 \%$ formalin. Characters used in this study are presented in Table 1. Morphometric characters were measured with vernier caliper (accuracy $0.02 \mathrm{~mm}$ ). locality.

Calculation of mean, minimum, maximum, standard deviation; coefficient of variation in both male and female were implemented separately using SPSS Ver. 16.0.1 statistical package (SPSS Inc., Chigaco, IL, USA).

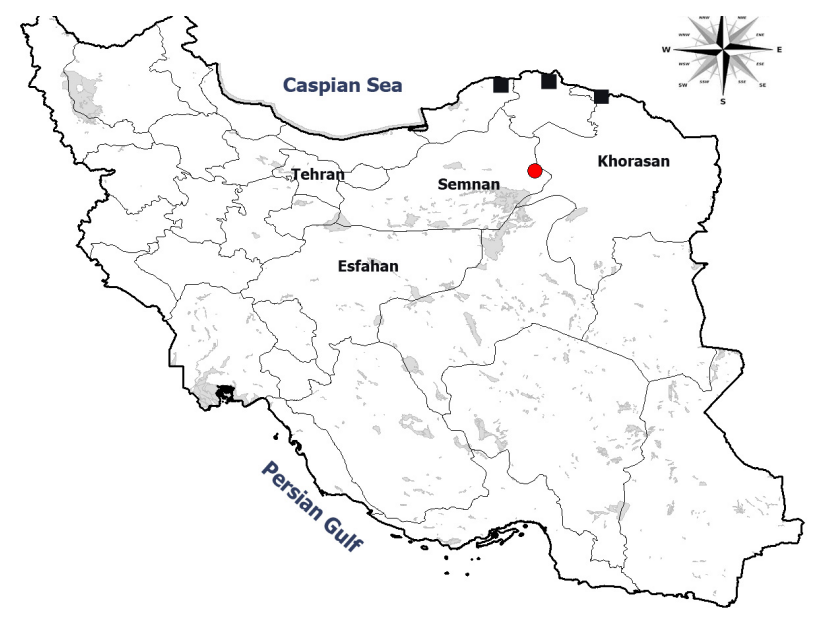

FIgURE 2. Phrynocephalus mystaceus type locality, square: previous localities (Anderson 1999), circle: new locality. 
In order to investigate Sexual dimorphism, we examined distribution and variances of each character using Kolmogorov-Smirnov and Levene Tests and finally one-way ANOVA was employed to assess differences between male and female characters.

Results of statistical analysis of morphological characters are shown in Table 2. According to Table 2, all of the characters exhibited normal distribution and variances but none of characters could reveal sexual dimorphism.

Color pattern: Dorsum is sandy; with black and white dots and reticulations; a row of larger dark blotches on each side of vertebral Line; vent white; ventral aspect of tail tip black chin and throat with gray reticulation (Figure3).

In this species TL is about equal to the SVL and in largest specimen collected: $\mathrm{SVL}=97.48$ and $\mathrm{TL}=101 \mathrm{~mm}$. Although Anderson had found a specimen with SVL=122.7 and $\mathrm{TL}=135.8 \mathrm{~mm}$ in Uzbekistan, the largest specimen that he had collected in Iran was a male with SVL=77.7 and $\mathrm{TL}=71 \mathrm{~mm}$.
In all specimens studied, there is a greatly enlarged scale (equal to about four adjacent scale) on each side of thorax behind maxilla and occasionally an additional scale or two slightly smaller adjacent to it. This property

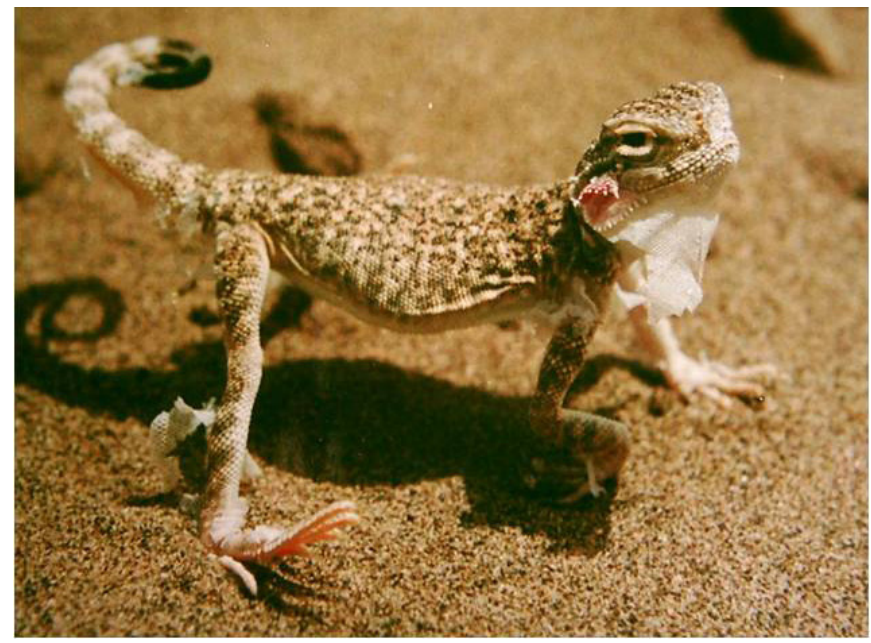

FIGURE 3. Phrynocepholus mystaceus in natural sandy habitat.

TABLE 1. The quantitative (metric and meristic) measured characters.

\begin{tabular}{ll}
\hline CHARACTERS & DEFINITION \\
\hline SVL.TL & SVL / TL \\
SVL & Length of snout to vent (from tip of snout to anterior edge of cloacae) \\
HW & Wide of head (at the widest point of head) \\
HL & Length of head (from tip of snout to posterior edge of tympanum) \\
TL & Tail length (from posterior edge of cloacae to tip of tail) \\
NS & Number of nasal scales \\
AB & Number of scales around body \\
BE & Number of scales between eyes in the head width \\
BLEL & Number of scales between labial and eye (right) \\
BLER & Number of scales between labial and eye (left) \\
LLR & Number of lower labial scales (right) \\
LLL & Number of lower labial scales (left) \\
SLR & Number of supralabials (right) \\
FT4L & Total number of lamellae under the left forth toe \\
FT4R & Total number of lamellae under the right forth toe \\
\hline
\end{tabular}

TABLE 2. Results of statistical analysis of morphological characters of the Phrynocephalu smystaceus from Semnan province of Iran. Mean, Maximum and minimum values for different characters in both male (M) and female (F) and result of Kolmogorov-Smirnov test (K.S), Levene's test (Lev), One-Way Analysis of Variance (CRD) are summarized.

\begin{tabular}{|c|c|c|c|c|c|c|c|c|c|c|c|c|c|c|c|}
\hline \multirow[b]{2}{*}{ Variable } & \multicolumn{2}{|c|}{ MEAN } & \multicolumn{2}{|c|}{ SD } & \multicolumn{2}{|c|}{ Min } & \multicolumn{2}{|c|}{ Max } & \multicolumn{2}{|c|}{ CV\% } & \multicolumn{2}{|c|}{$\mathbf{N}$} & \multicolumn{3}{|c|}{$\mathbf{F}$} \\
\hline & M & $\mathrm{F}$ & M & $\mathrm{F}$ & M & $\mathrm{F}$ & M & $\mathrm{F}$ & M & $\mathrm{F}$ & M & $\mathrm{F}$ & K.S & Lev & CRD \\
\hline SVL/TL & 0.80 & 1.01 & 0.05 & 0.30 & 0.93 & 0.97 & 1.04 & 1.03 & 5.10 & 2.90 & 3 & 4 & 0.929 & 0.385 & 0.487 \\
\hline NS & 2.00 & 2.00 & 0.00 & 0.00 & 2.00 & 2.00 & 2.00 & 2.00 & 0.00 & 0.00 & 3 & 4 & - & - & - \\
\hline BLEL & 3.00 & 3.00 & 0.00 & 0.00 & 3.00 & 3.00 & 3.00 & 3.00 & 0.00 & 0.00 & 3 & 4 & - & - & - \\
\hline BLER & 3.33 & 3.00 & 0.58 & 0.00 & 3.00 & 3.00 & 4.00 & 3.00 & 17.00 & 0.00 & 3 & 4 & 0.056 & 0.05 & 0.285 \\
\hline LLL & 9.00 & 9.50 & 1.41 & 1.29 & 8.00 & 3.00 & 10.00 & 11.90 & 15.00 & 13.00 & 2 & 4 & 0.955 & 0.116 & 0.247 \\
\hline SLL & 15.00 & 11.75 & 0.00 & 4.19 & 15.00 & 6.00 & 15.00 & 16.00 & 0.00 & 35.00 & 3 & 4 & 0.65 & 0.110 & 0.665 \\
\hline LLR & 8.50 & 11.75 & 2.12 & 3.59 & 7.00 & 9.00 & 10.00 & 17.00 & 24.00 & 30.00 & 2 & 4 & 0.677 & 0.481 & 0.317 \\
\hline SLR & 15.33 & 16.25 & 1.53 & 2.22 & 14.00 & 14.00 & 17.00 & 19.00 & 9.00 & 13.00 & 3 & 4 & 0.78 & 0.361 & 0.569 \\
\hline FT4L & 18.33 & 18.50 & 1.15 & 1.73 & 17.00 & 17.00 & 19.00 & 20.00 & 8.00 & 9.00 & 3 & 4 & 0.66 & 0.05 & 0.892 \\
\hline FT4R & 17.67 & 19.00 & 0.85 & 1.41 & 17.00 & 17.00 & 18.00 & 20.00 & 3.000 & 7.40 & 3 & 4 & 0.93 & 0.310 & 0.191 \\
\hline HW & 20.38 & 19.18 & 3.37 & 7.49 & 18.00 & 13.04 & 22.76 & 28.50 & 16.00 & 39.00 & 2 & 4 & 0.98 & 0.138 & 0.846 \\
\hline HL & 24.25 & 20.20 & 2.47 & 6.86 & 22.50 & 13.48 & 26.00 & 29.00 & 10.00 & 33.00 & 2 & 4 & 0.97 & 0.192 & 0.483 \\
\hline $\mathrm{BE}$ & 30.33 & 31.50 & 2.08 & 3.11 & 28.00 & 28.00 & 32.00 & 35.00 & 6.80 & 9.80 & 3 & 4 & 0.99 & 0.288 & 0.601 \\
\hline SVL & 68.42 & 68.83 & 20.72 & 25.65 & 47.66 & 43.24 & 89.10 & 97.48 & 30.00 & 37.00 & 3 & 4 & 0.91 & 0.331 & 0.982 \\
\hline TL & 69.07 & 68.91 & 17.42 & 27.26 & 51.20 & 42.88 & 86.00 & 101.00 & 25.00 & 39.00 & 3 & 4 & 0.88 & 0.179 & 0.393 \\
\hline $\mathrm{AB}$ & 117.33 & 94.75 & 8.08 & 60.77 & 110.00 & 5.00 & 126.00 & 138.00 & 6.00 & 64.00 & 3 & 4 & 0.88 & 0.179 & 0.393 \\
\hline
\end{tabular}


has reported by Anderson in other specimens of other regions; such scalation is absent in all other species of Phrynocephalus examined (all southwest Asian species and several Central Asian forms) (Anderson 1999). Therefore these two characters are added to former morphological key characters of this species.

Fringes on digits (numbered 17-18) are adaptation to its special habitat. Since the whole distribution of this Lizard is sand dunes.

Terentjev and Chernov (1949) recognize two subspecies from entire distribution range. Two subspecies of this species, P. m. galli and P. m. mystaceus are subject of debate. Anderson had found specimens from Iran appear to be intermediate between two taxa. They agree with $P . m$. galli in color pattern and fringes on the digits and show a better fit to P. m. mystaceus in the fold at the corners of mouth dose not reach the neck, and also that the tail is developed. Moreover, keels of breast and belly are said to be strongly developed in P. m. galli and less distinct in P. m. mystaceus (Anderson 1999). However, Anderson (1999) does not attribute Iranian specimens to any of these subspecies. Golubev and Sattorov (1992) regard $P$. mystaceus as a monotypic species based on study of morphological characters throughout the range. Present work revealed that morphology alone is probably not sufficient for fine resolution of subspecies. Combination of both morphological and molecular methods is recommended to demonstrate if $P$. mystaceus is a monotypic or polytypic species.

\section{Literature Cited}

Anderson, S.C. 1974. Preliminary key to the Turtles, Lizards and amphisbaenians of Iran. Fieldiana: Zoology 65(4): 27-44.

Anderson, S.C. 1999. The Lizards of Iran, Ithaca, New York, USA: Society for the Study of Amphibians and Reptiles. $415 \mathrm{pp}$.

Golubev, M.L. and T.S. Sattorov. 1992. On the intraspecific structure and extraspecific relations of the ear-folded toad agama Phrynocephalus mystaceus (Reptilia, Agamidae). Vestnik Zoologii 3: 26-32 [in Russian].

SPSS, 2007. SPSS 16.0.1 for Windows. Chicago: SPSS Inc. Accessible at http://www.spss.com.

Terentjev P.V. and S.A. Chernov. 1949. Opredelitel Presmykayushchikhsya i Zemnovodnykh (Guide to Reptile and Amphibians). Moscow and Leningrad: Soviet Science Prees. 340 pp. [In Russian].

Tuck, Robert G., Jr. 1979. Notes on the Turan Biosphere Reserve herpetofauna, northwestern Iran. Bulletin of the Maryland Herpetological Society 15(4): 95-123.

Welch K.R.G. 1983. Herpetology of Europe and Southwest Asia: A checklist and Bibliography of the Order Amphisbaenia, Sauria and Serpentes. Malabar, Florida: Robert E. Krieger Publishing Company. Viii+135 pp.

Wermuth H. 1967. Liste der rezenten Amphibien und Reptilien: Agamidae. Das Tierreich. Berlin: Walter de Gruyter. vol. 86: xiv+127 pp.

RECEIVED: October 2013

ACCEPTED: February 2014

PUBLISHED ONLINE: May 2014

EDITORIAL RESPONSIBILITY: Perry Wood 